\title{
Aproximación al proceso de autoconstrucción de las marcas-agencia
}

Eva Quintas Froufe I eqfroufe@uvigo.es

UNIVERSIDAD DE VIGO

Natalia Quintas Froufe | natalia.quintas@ua.es

UNIVERSIDAD DE ALICANTE

Resumen: Este artículo analiza las empresas publicitarias en su dimensión de marcas, incidiendo en el reto que supone dado el actual contexto publicitario globalizado. En la misma línea temática, profundizaremos en el proceso de construcción de marca por parte de las empresas de publicidad a través de la identificación de diferentes acciones comunicativas dirigidas a dos entornos o públicos: externo e interno.

Palabras clave: agencias de publicidad, marcas, globalización.

Abstract : This article analyzes the advertising agencies in their dimension of brands, focusing on the challenge that it supposes in view of the current globalized advertising context. In the same thematic line, we will study the process of construction of brands by the advertising agencies by means of the identification of different communicative actions aimed at two environments or publics: external and internal.

Key words: advertising agencies, brands, globalization. 


\title{
1. Introducción
}

La publicidad ha experimentado una notable evolución que la ha llevado a convertirse en una disciplina con entidad propia que, según el profesor Gómez Sánchez (2002) ha ido progresivamente tomando consciencia de sí misma:

\begin{abstract}
La publicidad no ha permanecido ajena al perpetuo revisionismo a que está sujeta toda actividad humana $y$, de ser una disciplina de comunicación que vivía por y para el producto (del mismo modo que el escritor de discursos regala su verbo experto al locutor que lo pronuncia), ha pasado a conformar una entidad autoconsciente que otorga premios, suscita programas monográficos y artículos periodísticos, convierte canciones olvidadas en superventas, hace de sus artífices y actores estrellas contemporáneas [...]
\end{abstract}

En el proceso de autoconsciencia que ha experimentado la publicidad, las agencias son o deberían ser conscientes de la trascendencia de crear su propia marca-agencia perdurable, un imperativo de máxima urgencia dado el actual escenario publicitario.

Desde los albores de la profesión, las agencias de publicidad cuentan con sus propias identidades, estrategias de comunicación y filosofías de trabajo, a pesar de los constantes cambios en su estructura y en sus equipos humanos. No en vano, las transformaciones empresariales que han tenido lugar en la segunda mitad del siglo XX han provocado el debilitamiento de las marcas-agencia, al contrario que "la época en la que los nombres de las agencias representaban una filosofía publicitaria y una personalidad distinta como los productos de marca" (Kleppner, Russell y Lane, 1994: 125) época en la que Bill Bernbach, David Ogilvy o Leo Burnett eran líderes originales de sus agencias y de sus respectivas filosofías publicitarias. De hecho, gran parte de las agencias multinacionales conservan como referencia las figuras de sus fundadores cuyas personalidades fueron el origen de sus propios negocios y su particular sello diferenciador: Frank Lowe, los hermanos Saatchi, Charles Austin Bates, Jacques Séguéla, Jean Marie Dru o Bill Bernbach son muestras de ello. En la actualidad, las agencias multinacionales tratan de mantener intactas en sus filiales sus respectivas filosofías profesionales y culturas de empresa diferenciadas, un reto de gran complejidad teniendo en cuenta las diferencias culturales que presenta cada nacionalidad.

Las agencias se ven a sí mismas como marcas circulando en una misma arena competitiva en la que deben posicionarse como líderes, como las más creativas o las más eficaces y luchar año tras año por figurar en el top of mind de agencias de publicidad. Sin embargo, el factor diferenciador con respecto al resto de marcas radica en que las agencias deben autoconstruir sus propias marcas-agencia al mismo tiempo que construyen las de sus clientes (figs. 1 y 2 ).

Por tanto, en la primera parte de este artículo trataremos de aproximarnos a las empresas publicitarias en su dimensión de marcas y en la segunda parte, identificaremos las principales acciones autopublicitarias emprendidas por éstas. Debido a la ausencia de bibliografía específica sobre el tema en cuestión, para sustentar las afirmaciones teóricas de 
este artículo se ha recurrido a la revisión hemerográfica de publicaciones periódicas especializadas (El Publicista, Anuncios y Control) así como a los cuestionarios constituidos por preguntas de repuesta abierta enviados a una selección de agencias de publicidad con sede en España (Bassat Ogilvy, DDB España, Euro RSCG, Grey, Young \& Rubicam, McCann Erickson, Sra. Rushmore, Tapsa, TBWA España y Tiempo BBDO) con la finalidad de concluir a qué públicos se dirigen fundamentalmente estas agencias y qué tipo de iniciativas llevan a cabo para construir su personalidad como marcas. Cronológicamente, las acciones autopublicitarias señaladas se desarrollan en la actualidad, no obstante, haremos referencia a antecedentes históricos que contribuirán a una óptima comprensión de los mismos. No obstante, en primer lugar, es necesario reflexionar sobre el contexto publicitario globalizado en el que se desarrollan las marcas-agencia.

\section{La globalización publicitaria}

Kleppner señalaba que estamos inmersos en un proceso de internacionalización imparable que afecta a todas las áreas, fundamentalmente económicas, entre las cuales la publicidad como actividad mercantil no constituye una excepción (Kleppner, Russell y Verrill, 1994: 725).

Efectuando una traslación a la industria publicitaria, el término globalización -designación atribuida a Theodore Levitt- aplicado a la publicidad sugiere que "las compañías pueden desarrollar estrategias mundiales de marketing y de publicidad para sus productos" (1994: 725). Desde nuestra perspectiva, la internacionalización del sector publicitario se refleja en dos dimensiones:

Por una parte, la publicidad multinacional entendida como "la coordinación y ejecución de campañas publicitarias dirigidas a una serie de países" (Russell y Lane, 2001: 631) que surge por la necesidad de aquellos anunciantes que expanden sus negocios en el ámbito internacional. Este tipo de publicidad puede ser elaborada desde un enfoque de estandarización o, por el contrario, de localismo.

Por otra parte, la internacionalización se refleja en la existencia de agencias de publicidad supranacionales. La publicidad multinacional exige la preexistencia de una compañía de publicidad a la que encomendarle su ejecución en todos aquellos países en los que el negocio experimente su expansión. Es así como surgen las agencias delegadas o filiales que "actúan como delegaciones de organizaciones más grandes. Aunque hacen su trabajo de captación de clientes normal, se benefician del know how, los servicios de diseño $y$, en ocasiones, las relaciones de la empresa matriz" (Gutiérrez, 2002: 78). 


\subsection{Origen}

Según Luis Bassat, la globalización dio comienzo cuando las empresas norteamericanas decidieron vender sus productos fuera de sus fronteras. Particularmente, Bassat sitúa el nacimiento del concepto hacia 1968 en un lugar concreto, Estados Unidos, inspirado por el rápido desarrollo de las grandes multinacionales americanas y por otra parte, por el aumento de poder de ciertas agencias de publicidad de Madison Avenue (1999: 236). Según su visión, las agencias de publicidad no están ni a favor ni en contra de la globalización pues están donde están sus clientes, y a su vez, su carácter está muy marcado por el carácter de los mismos. En cuanto al futuro de este fenómeno, Bassat estima que el movimiento global es irreversible, sin embargo, considera que pervivirán las agencias de publicidad locales y globales debido a la existencia de clientes locales y globales.

Por el contrario, Joaquín Lorente aprecia que "la globalización es un fenómeno tan antiguo como la historia de la humanidad. Los grandes imperios fueron multinacionales con poder político" (2002: 3) aun reconociendo que el proceso globalizador es imparable e indiscutible.

Otros profesionales publicitarios conciben este proceso no como globalización sino como la invasión de una cultura - la estadounidense- sobre las restantes. Con respecto a este tema, resulta ineludible citar a la agencia J. Walter Thompson que destacó por ser la primera en desembarcar en suelo extranjero instalando en 1899 su primera "oficina de ventas" en Europa, concretamente, en Londres. Según Mattelart, la sede londinense se convirtió en una verdadera filial cuando su cliente General Motors invitó a J. Walter Thompson a representarla a lo largo del mundo, en todos aquellos lugares donde la empresa tuviese fábricas o cadenas de montaje de automóviles. Así, la instalación de la estadounidense J. Walter Thompson en distintas capitales del mundo inauguró esta tendencia, una estrategia expansiva que le supondrá ser considerada como "el parangón del modelo imperial de internacionalización o [...] del modelo colonial" (Mattelart, 1989: 29).

\subsection{Desarrollo}

Russell y Lane señalaban que fue en las décadas de 1940 y 1950 cuando McCann Erickson y J. Walter Thompson comenzaron a llevar sus agencias de Estados Unidos al campo internacional inaugurando sucursales extranjeras de país en país (2001: 636). Inicialmente, estas agencias surgieron con la finalidad de gestionar las cuentas de clientes internacionales allí donde estas multinacionales estadounidenses se ubicaban. Mattelart asevera al respecto que "la posición hegemónica de las redes de agencias norteamericanas no hacía sino traducir una supremacía industrial y comercial" (1989: 29).

La escasa practicidad de esta tendencia dio lugar a una solución más operativa consistente en que las grandes agencias adquiriesen intereses en agencias publicitarias del país en cuyo mercado deseasen introducirse. Por esta razón, en la década de los 70, la mayor parte de las agencias estadounidenses pasó de tener oficinas en el extranjero, a establecer alguna forma 
de empresa conjunta (joint venture) o de propiedad minoritaria de las agencias extranjeras existentes.

En la década de los 80 , el perfil de la industria publicitaria internacional experimentó un cambio sustancial con el incipiente proceso de formación de empresas globales especializadas en la comunicación publicitaria (McDonough y Egolf, 2003: 680). Éste será el inicio de una tendencia ya irreversible que provocó la concentración de la industria publicitaria en grandes holdings o grupos de comunicación, inaugurando la modernidad mediática ya que, según Mattelart, "la historia de la formación de las redes publicitarias internacionales es la historia de las primeras vías de acceso a la llamada modernidad mediática" (1989: 53).

\subsection{Estado actual}

La estructura del mercado publicitario a nivel internacional presenta una clara propensión a la concentración como consecuencia de la globalización. Este proceso integrador comenzó a experimentarse en los años $80 \mathrm{y}$, tras múltiples operaciones, se ha consolidado desembocando en que gran parte de la industria publicitaria esté concentrada en básicamente seis grandes holdings de carácter internacional que se reparten la industria o "tarta" publicitaria mundial: Omnicom Group (Nueva York), WPP Group (Londres), Interpublic Group of Companies (Nueva York), Publicis Groupe (París), Dentsu (Tokio) y Havas (Suresnes, Francia).

Teniendo en cuenta este aspecto estructural, al observar el panorama publicitario internacional podemos distinguir las diferentes estructuras que componen la industria publicitaria:

En primer lugar, en la cúspide de la pirámide se sitúan los grandes holdings internacionales también denominados macrogrupos o cadenas de mega-agencias. Se trata de grupos de empresas con un radio de acción de alcance internacional integrados a su vez por redes internacionales de empresas que ofrecen servicios publicitarios.

En segundo lugar, podemos distinguir las siguientes tipologías de agencias de publicidad: las redes internacionales de agencias de publicidad tales como BBDO, McCann Erickson, Saatchi \& Saatchi que operan a nivel internacional a través de múltiples oficinas instaladas en diferentes países; son agencias creadas a partir de una matriz que progresivamente han ido expandiendo su campo de acción. Asimismo, detectamos la existencia de micro-redes que operan como las redes internacionales a menor escala y están compuestas por agencias que destacan por su talento creativo situadas en centros geográficos clave como Bartle Bogle Hegarty o Voluntarily United Group of Creative Agencies. Sin embargo, la vasta mayoría de las agencias de publicidad se ubican en un grupo de empresas de tamaño mediano y pequeño, que pueden ser independientes o estar participadas por grupos internacionales. 
En un tercer nivel, las propias agencias han experimentado su propia reingeniería en un empeño por ofrecer servicios plenos bajo una misma cabecera, bajo una misma marca. Esta tendencia a incorporar múltiples servicios especializados, señalada por López Lita, apunta hacia dos direcciones: "ofrecer todos los servicios bajo el techo de la agencia de publicidad, o contar con empresas especializadas en las diferentes disciplinas de manera que constituyan un grupo" (2001: 47). Como consecuencia, las agencias grandes y la mayoría de las medianas presentan una amplia gama de servicios de comunicación global al anunciante, además de los considerados convencionales. En este sentido, una agencia de publicidad ofrece servicios especializados convirtiéndose en una marca paraguas en cuyo seno abarca otras divisiones dedicadas a disciplinas específicas como el marketing directo, el diseño corporativo, la publicidad en la red, la promoción de eventos, la consultoría estratégica o el marketing farmacéutico.

\section{Proceso de autoconstrucción de las marcas-agencia}

\subsection{Definición y componentes}

Si tenemos en cuenta la definición de marca enunciada por David A. Aaker: "un nombre y/o símbolo distintivo (como un logotipo, marca registrada o diseño de envase) para identificar los productos o servicios de un fabricante o grupo de fabricantes y para diferenciar aquellos productos o servicios de los de su competencia" (1994: 8), podemos afirmar que cada agencia de publicidad constituye su propia marca. La mayoría de las agencias cuentan con un símbolo distintivo que identifica sus servicios, ya sean proporcionados por una sola agencia de publicidad o por un grupo constituido por empresas especializadas, con la finalidad de diferenciarse de la competencia.

A continuación, recurriremos a Joan Costa quien proporciona una definición de la marca que integra el desglose de sus elementos constitutivos. Costa establece que las marcas son resultado de una combinación de tres elementos visuales: el signo visual que se transforma por medio del diseño en logotipo (logos = palabra o idea de base, tipo = caracteres de la industria gutemberguiana), el signo icónico que es el símbolo de la marca y los colores distintivos, a los que define como señales/signo (2004: 25-26).

Teniendo en cuenta estos elementos constitutivos, podemos afirmar que la práctica totalidad de agencias cuenta con un signo visual identificativo y diferencial (fig. 3). En cuanto al signo icónico, no siempre las agencias lo presentan (por ejemplo, en sus inicios, el signo icónico de la agencia de publicidad J. Walter Thompson era un símbolo compuesto por un búho y una lámpara, símbolos de la sabiduría y de la ciencia respectivamente). Y con relación a los colores corporativos, determinadas agencias de publicidad han adoptado un color como atributo o elemento identificativo que preside gran parte de sus mensajes publicitarios, al igual que muchas marcas comerciales: Bassat Ogilvy ha apostado por el cromatismo corporativo rojo, Young \& Rubicam por el azul o DDB por el amarillo (fig. 4). 
Aunque pueden contar con una identidad corporativa diferenciada, las agencias de publicidad no constituyen una marca en el sentido habitual sino que se trata de un tipo de marca "desconocida" para el común del público ya que en España no es frecuente que el nombre o logotipo de la agencias figure en las piezas de las campañas publicitarias. Lo cierto es que sus nombres y sus respectivos trabajos son conocidos por los profesionales, académicos y estudiantes de la materia publicitaria y de disciplinas adyacentes, pero no por el gran público. No es frecuente delatar la autoría del mensaje publicitario a menos que la campaña o el anuncio en cuestión suscite polémica o goce de gran aceptación y fruto de ello, sea objeto de atención por parte de la opinión pública.

Tal como había señalado previamente Peninou, Ferrer Roselló hizo referencia a la posibilidad de que la agencia como emisor figurase en el mensaje publicitario a modo de firma. Por ello, este autor contempla una categoría dentro de la clasificación de los mensajes publicitarios que denomina "mensaje de referencia al emisor" cuya función consiste en remitir a la identidad de su autor, que en la mayoría de los casos se refiere a la agencia publicitaria. Sin embargo, aclara su excepcionalidad en tres sentidos: en cuanto a su disposición, la inscripción es de lo más discreto y marginal, va colocada en un plano perpendicular al de la lectura; en relación con su presencia en los medios, este tipo de mensajes es muy escaso en los spots y nulo en los radiofónicos y por último, teniendo en cuenta su relevancia, concluye que "la importancia que tiene para la mayoría del público es más bien escasa, se dirige a profesionales industriales" (1992: 320), es decir, se dirige a un público objetivo fundamentalmente profesional.

\subsection{Filosofía de las marcas-agencia}

En la actualidad, las agencias de publicidad multinacionales presentan una filosofía única a modo de eslogan que las diferencia dentro del competitivo panorama en el que coexisten, que permite singularizarlas y en último término, contribuye a que su público las identifique en el ecosistema de marcas que componen el mercado de agencias publicitarias.

Las filosofías de estas empresas constituyen prácticamente una declaración de principios cuyo nacimiento es simultáneo al de la agencia, tienen vocación de perdurabilidad y son exportables a todos aquellos países en los que las agencias se instalen. Estas filosofías tienen como finalidad facilitar la identificación y diferenciación, al mismo tiempo que son una síntesis de su particular enfoque o modo de hacer como creadores de publicidad.

Resumir en una sola expresión la propia concepción de la agencia de publicidad ha sido una constante en la profesión desde los orígenes de la misma, de hecho, ya en 1880, uno de los publicitarios pioneros, Francis Wayland Ayer anunciaba sus propios servicios con la siguiente expresión: "Hacerlo eterno trae éxito" (Eguizábal, 1998: 206). Otra de las agencias de publicidad norteamericana pioneras Lord \& Thomas contaba con su propia revista titulada Judicious Advertising, título que hacía referencia a su ideal de negocio publicitario: "advertise 
judiciously". Ejemplos de ello son los siguientes eslóganes: "Better ideas, better results" de DDB, "Truth well told" de McCann Erickson, "Disruptive Ideas" de TBWA o "The work. The work. The work" del grupo BBDO (fig. 5).

Otra forma de entender las filosofías de las agencias radica en concebirlas como metodologías de trabajo. En este sentido, Pérez Ruiz afirma que una de las principales aportaciones derivadas de la instalación de las agencias transnacionales en nuestro país, además de la definición de los distintos departamentos de la agencia, han sido las filosofías de trabajo importadas cuya aplicación fue patente en la publicidad española (2003: 193). EI citado autor comprende las filosofías de agencia como "un documento en el que se recogía la metodología de trabajo de las agencias, una especie de modelo particular de procedimiento que aplicaban a la resolución de las campañas" (2003: 341).

Hoy en día, en el caso de las agencias multinacionales, este documento se ha traducido en una serie de herramientas estratégicas o tipos de estudios patentados en aras de facilitar la resolución de los problemas de comunicación del cliente y diferenciar su know how frente a las demás agencias del mercado.

\subsection{Estilos publicitarios}

Las agencias de publicidad presentan diferencias sustanciales en las formas de concebir sus mensajes publicitarios. Sus particulares estilos publicitarios se plasmarán en las campañas que ejecuten para sus clientes y en las suyas propias, en éstas últimas podrán reflejarlos con mayor libertad y menor grado de condicionamiento. Eguizábal establece diferencias elementales entre los planteamientos o enfoques de distintas agencias ya en sus inicios: Ogilvy desarrollaba una publicidad sofisticada, en McCann Erickson se apoyaban en la investigación motivacional mientras que en J. Walter Thompson se basaban en investigaciones sobre el mercado y el consumidor, Bill Bernbach defendía por su parte el humor y la originalidad en los anuncios y Leo Burnett seguía el estilo directo de la denominada escuela de Chicago, frente a la escuela neoyorquina conformada por las restantes agencias instaladas en Madison Avenue (1998: 339).

Frente a la disparidad de enfoques existentes, en la Encyclopedia of Advertising se establece una categorización basada en dos orientaciones de venta que pueden adoptar las empresas publicitarias: hard-sell frente a soft-sell advertising, modalidades sobre las cuales se sustentará la filosofía de la agencia y que desde siempre han generado debate sobre su eficacia (McDonough y Egolf: 716-719).

La denominada hard-sell advertising se basa fundamentalmente en el reason why del cual había sido maestro Claude C. Hopkins. Los mensajes publicitarios que siguen esta orientación se centran en ofrecer al consumidor de forma directa los beneficios que el producto anunciado puede proporcionarle. Esta perspectiva se sustenta en la base de que el 
proceso de toma de decisiones por parte del consumidor es racional, fruto de justificaciones razonadas.

El nacimiento de esta orientación se remonta a principios del siglo XX y cabe destacar a Rosser Reeves - de la agencia Ted Bates \& Co.- como uno de los representantes de la misma. Reeves sostenía que se debía proporcionar al consumidor un único argumento de venta (USP, Unique Selling Proposition) que reuniese los siguientes requisitos: expresar un beneficio del producto, ser único y además, vender.

La publicidad clasificada como soft-sell advertising es más sutil e indirecta, su interés se centra en evocar una respuesta emocional positiva hacia la empresa, la marca o el producto objeto de la publicidad. Para provocar estas respuestas emocionales, los mensajes publicitarios utilizan con frecuencia el humor ya que desde esta perspectiva, el proceso de decisión de los consumidores está basado en los sentimientos.

En la década de 1930, Raymond Rubicam continuaría con esta tendencia en los trabajos publicitarios encomendados a su agencia Young \& Rubicam. Tras la Segunda Guerra Mundial, la agencia de publicidad paradigmática en soft-sell advertising será Doyle Dane Bernbach (DDB) al poner todo su énfasis en la resolución creativa del anuncio aunque ello implicase sacrificar el contenido. Tal como sintetiza Pere Soler refiriéndose a Bernbach "este publicitario representa la pura intuición, la publicidad sin reglas, sin caminos marcados. Su obsesión es la búsqueda de la originalidad" (1997: 219).

Otras agencias no se decantan por ninguna de estas opciones situándose en un estadio intermedio al debatirse en una síntesis de los dos enfoques descritos. David Ogilvy, por su parte, aunque priorizaba el contenido del mensaje sobre la forma, sostenía que la emoción era incluso más determinante que la razón en el ser humano. Ogilvy defendía que la brand image o imagen de marca podía ser más decisiva que un argumento racional, anteponiendo la importancia de la personalidad de la marca al producto en sí. Igualmente, Leo Burnett mezcló ambas tendencias utilizando para sus creaciones publicitarias el drama (un método de soft-sell advertising) ofreciendo al mismo tiempo información sobre el producto (enfoque próximo a hard-sell advertising). Estas tendencias continúan, a día de hoy, siendo objeto de debate.

\section{Acciones autopublicitarias y sus públicos prioritarios}

La comunicación por parte de las agencias de publicidad para construir su propia marcaagencia se dirige a un doble público: externo e interno. Desde un punto de vista interno, interaccionan con los trabajadores de la compañía y como público externo, se dirigen a diferentes stakeholders (accionistas, clientes, administración, competidores, instituciones financieras, etc.) 
Teniendo en cuenta lo establecido, las agencias de publicidad han de presentarse coherentemente a través de una doble dimensión interna y externa en la que profundizaremos a continuación. La mayor parte de las iniciativas que señalaremos hacen alusión a las agencias de mayor tamaño o redes internacionales puesto que sus recursos económicos repercuten directamente en la posibilidad de emprender más acciones de autopublicidad. Asimismo, estructuraremos estas acciones atendiendo al tipo de público al que se dirigen los publicitarios, destacando sus receptores prioritarios.

\subsection{Públicos externos}

Uno de los públicos externos preferentes de las agencias de publicidad es el entorno empresarial constituido por anunciantes que pueden ser clientes actuales o potenciales. Las principales iniciativas encaminadas a diferenciarse de las restantes agencias de cara a sus clientes pueden ser: el desarrollo de una identidad visual corporativa diferenciada, la creación de una sede diferencial así como la edición de anuarios de agencia o publicaciones promovidas por agencias en particular en las que recopilan sus campañas más destacables. A nivel nacional, MMLB publicó durante su existencia el denominado El libro de la agencia de periodicidad anual "donde existía un trabajo literario de tipo profesional y la reproducción de las mejores realizaciones de la agencia" (Lorente, 1995: 149) que era enviado a sus clientes tanto potenciales como reales.

En segundo lugar, las agencias dirigen parte de sus actividades al entorno universitario mediante la organización de concursos con el objetivo de la captación de potencial talento creativo. Asimismo, los seminarios y conferencias impartidas por miembros de la agencia con experiencia acreditada constituyen siempre una modalidad de autopromoción. Entre las iniciativas dirigidas a este colectivo, cabe destacar la implicación institucional de las agencias de publicidad con las escuelas, universidades o centros docentes en los que se imparte la disciplina de publicidad. Esta unión que fusiona el mundo académico y el profesional se describe como "fructífera en ambos sentidos: si la agencia aporta al mundo académico su profesionalidad, la contrapartida de éste no es menos importante como cantera de nuevos profesionales" (Sáez, 2005: 20-21). Concretamente, las empresas publicitarias colaboran con la oferta docente sobre publicidad y marketing que en España se articula en torno a licenciaturas, másters, seminarios o cursos especializados. Del mismo modo, cabe mencionar la publicación de diccionarios monográficos para estudiantes, investigadores y docentes.

En tercer lugar, es necesario citar una serie de acciones de comunicación dirigidas fundamentalmente al entorno profesional. Un ejemplo paradigmático serían las publicaciones con carácter de manual publicitario elaboradas por los representantes de las agencias publicitarias, complementadas y enriquecidas con sus respectivas experiencias profesionales. Esta iniciativa de plasmar por escrito los conocimientos adquiridos en la práctica publicitaria tiene su origen a finales del siglo XIX (Eguizábal, 1998: 297). George P. Rowell fue autor del manual The men who advertise: an account of successful advertisers, 
together with hints on the methods of advertising (1870) y en 1874, la agencia N.W. Ayer \& Son publicó The science of advertising: a manual for advertisers en los que implícitamente se hace autopublicidad de la propia agencia puesto que las experiencias se remiten a las campañas realizadas por y en el seno de la misma. En España, el pionero Prat Gaballí editó La publicidad científica (1917) que reúne las lecciones impartidas en la Escuela de Altos Estudios Comerciales de Barcelona por este profesional. El libro rojo de la publicidad y El libro rojo de las marcas de Luis Bassat constituyen dos ejemplos significativos caracterizados por la repercusión de su lanzamiento editorial (fig. 6). Incluso existen publicaciones monográficas de agencias como McCann Erickson que cuenta con el libro Truth well told: McCann Erickson and the pioneering of global advertising (1994). Otros ejemplos de libros autopromocionales serían los clásicos blue books de la agencia J. Walter Thompson, una de las primeras publicaciones sobre publicidad. Estos libros denominados The Thompson blue book on advertising combinaban información sobre la importancia de la publicidad con trabajos propios de la agencia y fotografías de sus oficinas.

En esta misma línea es habitual la edición de memorias autobiográficas, una tendencia que inició en 1905 George P. Rowell con la publicación de Forty years an advertising agent 18651905, el primero de los numerosos libros de memorias de profesionales publicitarios que le sucederían hasta la actualidad. Por su parte, David Ogilvy escribió Confessions of an Advertising Man (1963), Ogilvy on advertising (1983) y Blood, brains and beer (1978) reeditado en España como una autobiografía bajo el nombre de Anotaciones privadas de David Ogilvy (1997).

Otra importante plataforma para la difusión de las actividades emprendidas por las agencias son las revistas de carácter profesional especializadas en el sector. La presencia de las agencias de publicidad en este tipo de publicaciones periódicas se plasma principalmente a través de dos vías: a través de noticias de actualidad sobre las empresas publicitarias cuyo contenido gira en torno a las cuentas adquiridas, movilidad de equipo humano, prácticas innovadoras, reconocimientos con los que ha sido galardonada la agencia, o bien mediante los mensajes autopublicitarios gráficos corporativos que las agencias insertan en sus páginas, fundamentalmente en las ediciones anuales o números especiales dedicados a las agencias. En relación con estas iniciativas de tipo editorial, cabe mencionar los anuarios del sector emprendidos por particulares $u$ otras entidades.

Las empresas de publicidad tienen su particular medio de difusión en los certámenes o festivales dedicados íntegramente a la creatividad publicitaria. Los reconocimientos y premios logrados tendrán repercusión principalmente en el sector puesto que sus marcas protagonizarán la información profesional inmediata.

Por último, cabe mencionar las iniciativas dirigidas a un entorno que denominamos global que abarca tanto a la sociedad en general como a los públicos citados previamente: 
Teniendo en cuenta los medios convencionales, las agencias de publicidad ocasionalmente hacen uso del medio exterior potenciando la gran selectividad geográfica que éste permite. Por otra parte, internet es uno de los medios por excelencia para potenciar la comunicación de la agencia con sus diferentes públicos en la medida en que su página web constituye la puerta de acceso al universo simbólico de la agencia, sirviendo como un recurso de información para explicitar su filosofía, simplificar la complejidad que pueda entrañar la estructura de la compañía y asimismo, como recurso de exhibición para mostrar sus piezas creativas (fig. 7).

En el ámbito social, las empresas manifiestan su vinculación con entidades y asociaciones de carácter marcadamente social, frecuentemente actuando como socios institucionales. Ejemplo de ello son el programa de colaboración que vincula a McCann Erickson con la Asociación Española contra el Cáncer o la Fundación DDB Cares (2001) puesta en marcha a raíz de los atentados del 11 de septiembre de 2001 en Nueva York. También es relevante la implicación cultural de las agencias de publicidad mediante el patrocinio o la organización de muestras o eventos relevantes para la disciplina publicitaria (fig. 8).

Consideramos digno de mención por su carácter pionero una iniciativa excepcional que se concretaba en un mensaje publicitario audiovisual no convencional: la agencia Euro RSCG Londres insertó un spot en los canales de determinadas compañías aéreas europeas y asiáticas cuyo eje giraba en torno a la importancia de ser los primeros y no en vano, la campaña presentaba como eslogan de cierre "be first" (fig. 9).

\subsection{Público interno}

Dentro de las iniciativas dirigidas al entorno interno de la compañía, diferenciamos tres categorías según su carácter informativo, implicativo o formativo destinadas a los propios integrantes de las agencias de publicidad que incluyen tanto acciones publicitarias como relaciones públicas:

Entre las iniciativas destinadas a la información de los empleados, destacan las revistas técnico-profesionales propias, publicaciones de carácter divulgativo o formativo que existen desde los orígenes de la actividad publicitaria profesional (Caro, 1995: 155-165). Estas publicaciones que nacen por iniciativa de las propias agencias han sido de gran utilidad para el desarrollo de la profesión publicitaria porque, según Eguizábal, "aunque servían como elemento de prestigio y de autopublicidad, contribuyeron decisivamente a difundir las experiencias y los conocimientos publicitarios" (1998: 205). En España, cabe citar los siguientes soportes impresos emprendidos por iniciativa de las propias agencias de publicidad, muchos de ellos incluyendo en su título la denominación de la propia empresa: por orden cronológico, cabe destacar entre otras Fama (Barcelona, mensual, 1919), Cuadernos Publicitarios Oeste (Barcelona, periodicidad irregular, 1947), Ideas Gisbert (Madrid, trimestral, 1961), Publidis informa (Madrid, mensual, 1961), Boletín Interdís 
(Madrid, semanal, 1966) y Cuadernos Interdís (Madrid, periodicidad irregular, monografías, 1966), Ideas Garsan (Madrid, bimensual, 1970), Creatividad MMLB (Barcelona, trimestral, 1982) y Cuadernos Contrapunto (edita Contrapunto, Madrid, periodicidad irregular, 1986).

Entre las iniciativas de implicación cuyo objetivo es la motivación e integración del personal en el entorno laboral de la agencia cabe mencionar: las campañas internas de marketing directo, la recolección de las mejores piezas publicitarias para su distribución interna así como las reuniones periódicas.

Las agencias de publicidad multinacionales convocan periódicamente a sus equipos en reuniones de carácter local, nacional o internacional con la finalidad de favorecer el flujo bilateral de información para así potenciar la implicación y satisfacción del público interno. Estas citas periódicas se desarrollarán a menor o mayor escala dependiendo del tamaño de la agencia. Estos encuentros sistemáticos "favorecen también el intercambio de ideas y la transferencia de experiencias de un mercado a otro, de una filial a otra" (Mattelart, 2000: 38). Los encuentros de carácter local son fundamentalmente reuniones de equipos creativos mientras que los encuentros nacionales e internacionales suelen coincidir con los acontecimientos publicitarios por excelencia, los festivales publicitarios. Además de favorecer el contacto personal entre los integrantes de la red, son citas que permiten la revisión de los estándares creativos por áreas geográficas.

Para facilitar la comunicación entre los trabajadores de la empresa, una herramienta esencial es la intranet, una red interna de comunicación corporativa utilizada únicamente por los empleados de la compañía que permite el flujo interno de información y el contacto constante entre los trabajadores o las agencias del grupo.

Por último, entre las iniciativas de formación, determinadas agencias han creado centros orientados a la formación de los profesionales de la agencia como las entidades Grey University, el Instituto de Comunicación Grey o DDBU (DDB University).

\section{Conclusiones}

Como síntesis de esta reflexión sobre el fenómeno de reorganización del sector y el papel que las marcas-agencia juegan en él, concluimos que el entorno en el que se ubica la agencia de publicidad del siglo XXI se caracteriza por las siguientes tendencias: una irrefrenable política de concentración de agencias que favorece el desarrollo de las estructuras multinacionales así como la creciente proliferación de servicios especializados.

Tras nuestro estudio, hemos concluido que las transformaciones estructurales que afectan al sector hacen cada vez más necesaria la proyección de la propia imagen de las agencias mediante la creación de una marca-agencia diferenciada. Si bien, hemos de añadir que los esfuerzos comunicativos por hacer llegar esta imagen a sus públicos se presentan débiles. 
En cuanto a los medios publicitarios predominantes empleados para difundir la propia comunicación de las agencias, éstas se dirigen a sus públicos fundamentalmente a través de medios no convencionales, como testimonio del auge de las acciones bellow the line frente a las tradicionales.

En definitiva, las agencias de publicidad que conforman el panorama publicitario actual, independientemente de su tamaño, constituyen su propia marca que deben autoconstruir y comunicar a sus diferentes públicos, externos e internos. No obstante, las vías para aproximar su marca a los diferentes públicos deberían seguir un planteamiento estratégico para ser completamente efectivas.

\section{Anexo}

\section{Construyendo marcas construimos la nuestra.}

\section{FCB / TAPSA}

FOOTE CONE \& BELDING

Madrid Barcelona Sevilla 913190462

Fuente: Anuncios, no 1092 (21 de febrero de 2005), p. 6.

Fig. 1. Inserción autopublicitaria fcb/tapsa.

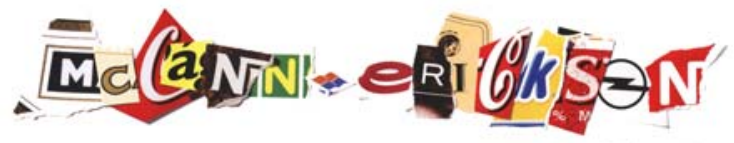

Fuente: El Publicista, (anuario de publicidad medios y agencias, 2003), p. 80.

Fig. 2. Inserción autopublicitaria McCann Erickson. 


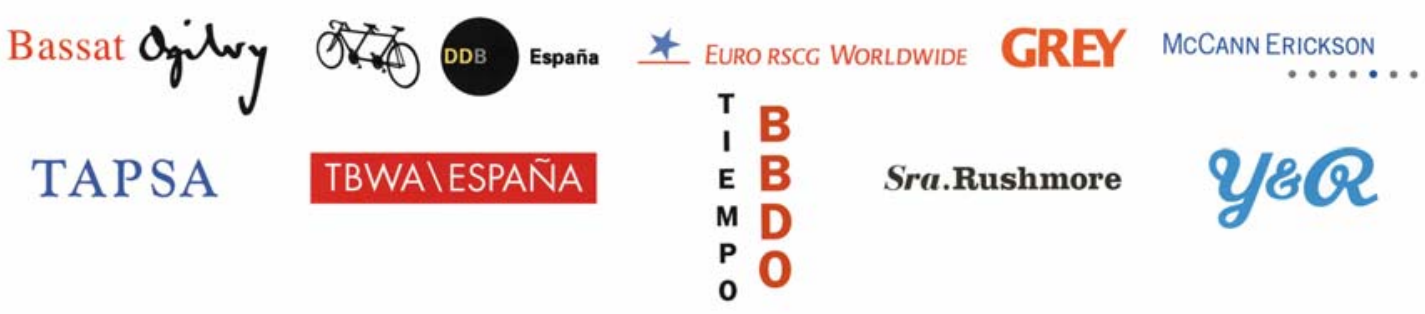

Fig. 3. I dentidad corporativa de las agencias objeto de estudio.

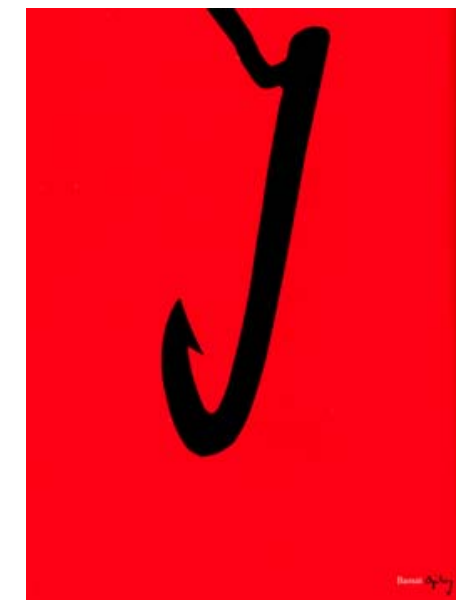

Fuente: El Publicista, (anuario agencias de publicidad y medios, 2005), p. 54

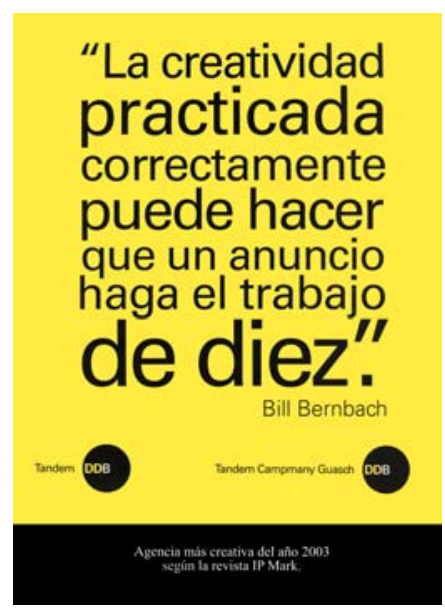

Fuente: IPMARK, № 605 (1-31 de julio de 2003), p. 21.

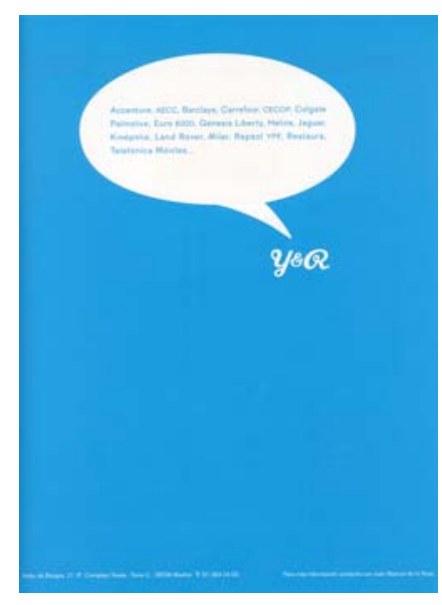

Fuente: Control, № 500 (abril de 2004, año 43), p. 51.

Fig. 4. I nserciones autopublicitarias: aplicación de cromatismos corporativos.

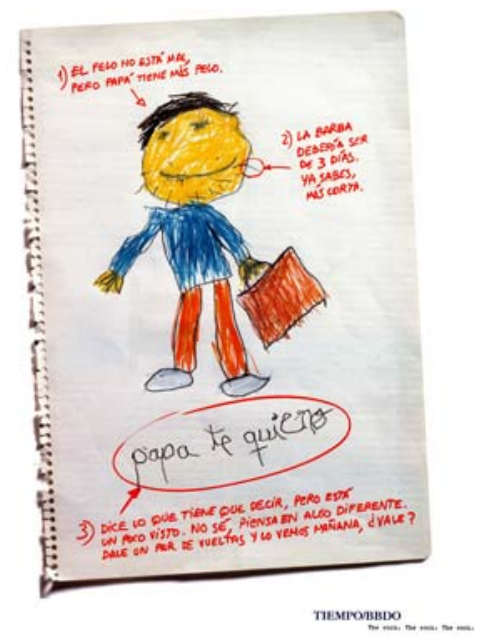

Fuente: IPMARK, № 559 (1-15 de abril de 2001), p. 153.

Fig. 5. Inserción autopublicitaria Tiempo BBDO. 


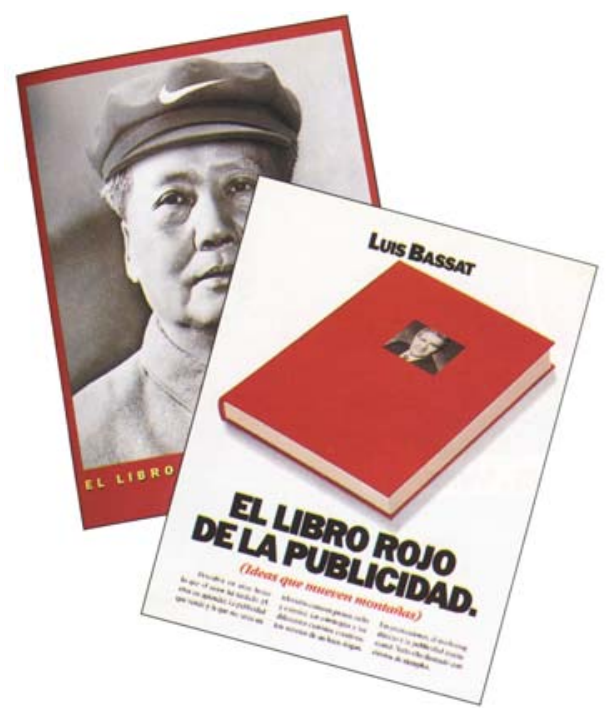

Fig. 6. El libro rojo de la publicidad y El libro rojo de las marcas.

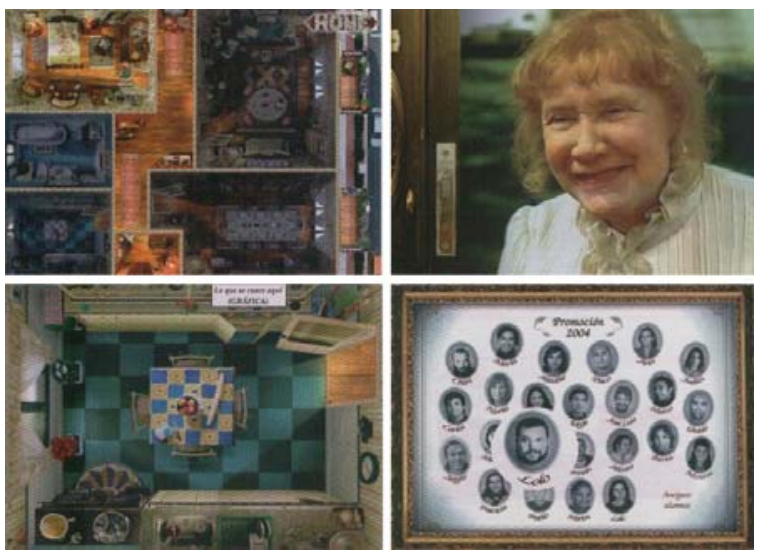

Fuente: www.srarushmore.com

Fig. 7. Página web de Sra. Rushmore.

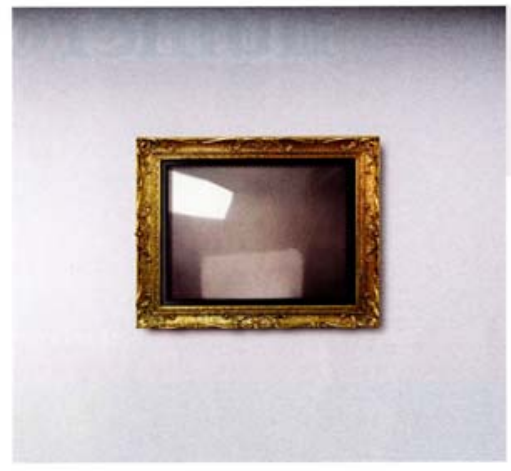

FCB/Tapsa trae la Colección de Publicidad del MoMa al Museo Nacional Centro de Arte Reina Sofía.

\section{FCB/TAPSA}

El Acto de Presentación de la Colección, que muestra las mejores producciones de publicidad reconocidas por la AICP y forma parte del Departamento de Películas y Medios del MoMa, tendrá lugar el 19 de Julio a las 20.00h. en el Salón de Actos del Museo Nacional Centro de Arte Reina Sofía.

Fuente: Anuncios, № 1112 (28 de julio de 2005), p. 8.

Fig . 8. Inserción autopublicitaria fcb/tapsa. 

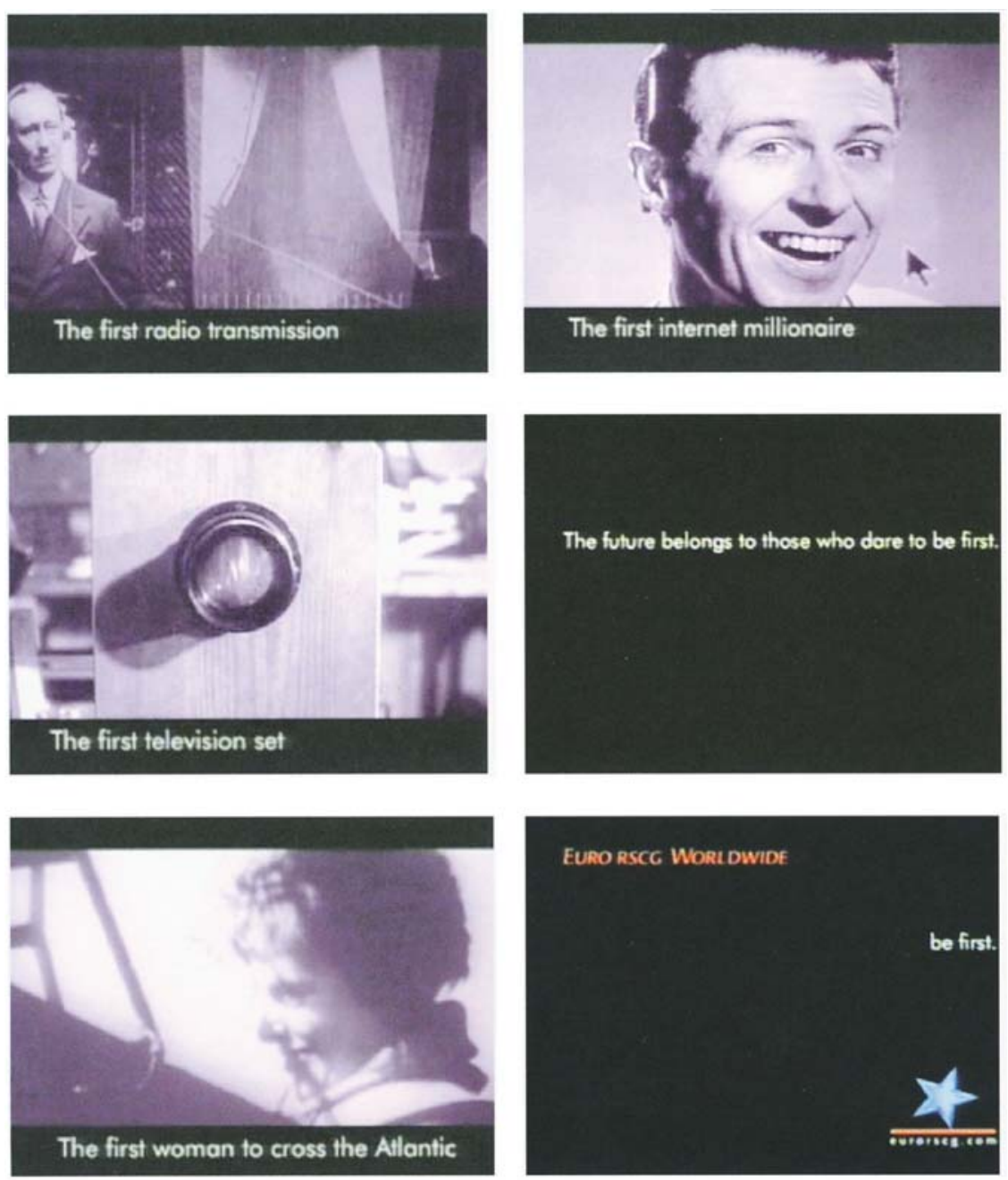

Fig. 9. Spot Euro RSCG. 


\section{REFERENCI AS BI BLI OGRÁFI CAS}

AAKER, David A. (1994): Gestión del valor de marca, capitalizar el valor de marca. Madrid, Díaz de Santos.

BASSAT, Luis (1999): El libro rojo de la publicidad. Madrid, Espasa Calpe.

CostA, Joan (2004): I magen de marca. Barcelona, Paidós.

Díaz Soloaga, Paloma (2002): El proceso de construcción de imagen de marca en Internet. Tesis doctoral presentada en la Universidad Complutense de Madrid.

EguizÁBAL, Raúl y CARO, Antonio (eds.) (1996): Medición, investigación e información de la publicidad. Madrid, Edipo.

EguizÁBAL, Raúl (1998): Historia de la publicidad. Madrid, Eresma \& Celeste.

GÓmEZ SÁNCHEZ, Diego (2002): “Hola, soy un anuncio. Un viaje hacia la autoconsciencia", monografía, en http//www.ucml.es/lamusa (Consultado: 17/06/2006).

Ferrer Roselló, Clemente (1992): La publicidad. Una teoría humanística de su estructura, método y ciencia. Tesis doctoral presentada en la Universidad Complutense de Madrid.

García Uceda, Mariola (2000): Las claves de la publicidad. Madrid, ESIC.

GonzÁlez, Francisco J. (2000): "La agencia de publicidad del nuevo milenio", en El Publicista, no extra (Milenios: los mejores del siglo XX. El siglo XXI que viene), p. 84 .

"Grey montará la Grey University y el Instituto de Comunicación Grey" (2002), en El Publicista, no 75 (1-15 diciembre 2002), p. 40.

GutiérReZ, Pedro Pablo (2002): La gestión de ventas en publicidad. Madrid, Complutense.

Kleppner, Otto, Russell, J. Thomas y Verrill, Glenn (1994): Publicidad. México DF, Prentice Hall Hispanoamericana.

“Las agencias ante la globalización” (2002), en El Publicista, no 58 (1-15 febrero 2002), p. 3.

“Las agencias de publicidad: un cambio obligado" (2004), en El Publicista, no 102, (1-15 abril 2004), pp. 22-25.

LÓPEZ LITA, Rafael (2001): Agencias de publicidad: evolución y posicionamiento futuro. Castellón de la Plana, Publicacions de la Universitat J aume I.

LORENTE, Joaquín (1995): Casi todo lo que sé de publicidad. Madrid, Folio.

“Marcas que ayudan a crear marcas" (2003) en Control, no extra (dossier de marcas I), pp. 186-192.

MATTELART, Armand (1989): La internacional publicitaria. Madrid, Fundesco. 
MATTELART, Armand (2000): La publicidad. Barcelona, Paidós.

MAYLES, Peter (1999): Viva la agencia: trampas y atajos en el mundo de la publicidad. Madrid, Eresma \& Celeste.

McDonough, John, Museum of Broadcast Communications y Egolf, Karen (eds.) (2003): The Advertising Age Encyclopedia of Advertising. Nueva York, Fitzroy Dearborn.

MedinA, Agustín (2004): Apuntes para un cambio de siglo publicitario. Madrid, Cinca.

MoLINÉ, Marçal (2000): La fuerza de la publicidad. Madrid, McGraw-Hill Interamericana.

OrtegA, Enrique (1999): La comunicación publicitaria. Madrid, Pirámide.

PÉreZ, Miguel Ángel (1996): Fundamentos de la estructuras de la publicidad. Madrid, Síntesis.

Russell, J. Thomas y LANe, W. Ronald (2001): Kleppner Publicidad. México DF, Pearson Educación.

SÁEZ, Maite (2005): “Las agencias van a la escuela”, en Anuncios, no 1112 (18-24 julio 2005), pp. 20-21.

SOLER, Pere (1997): Estrategias de comunicación y de marketing. Barcelona, Gestión 2000.

[Recibido: 05-11-2008. Aceptado (con necesidad de modificaciones): 17-04-2009. Recepción de la versión modificada: 25-06-2009] 